\title{
O que há de "Novo" na Química Supramolecular
}

\author{
FER NANDO PIN A *
}

\section{UM POUCO DE HISTÓRIA}

No já longínquo Setembro de 1984 acabado de chegar à cidade de Bolonha para aí iniciar o meu postDoc em Fotoquímica no grupo do Prof, Balzani, fui de improviso introduzido numa reunião onde se discutiam as estratégias para a investigação nos anos seguintes. Após assistir a um longo debate, fiquei com a sensação de que a Fotoquímica tradicional tinha os seus dias contados. Se tal me tivesse acontecido agora, teria sido mais cauteloso e não me tería passado pela cabeça traçar do mapa com tanta ligeireza (se bem que no inconsciente) uma inteira ciência. Mas nessa altura devo confessar foi a interpretação que dei (não necessariamente coincidente com aquilo que na realidade havia sido discutido).

De acordo com os presentes nessa reunião, a Fotoquímica em particular e a Química em geral, tinham já atingido um grau de conhecimento suficiente para se compreender os seus fenómenos básicos, e o grande desafio seria complicar o simples. Como mais tarde escreveriam Balzani e Scandola no seu livro Supramolecular Photochemistryl, ...nas últimas décadas o conhecimento ao nivel molecular fez progressos extraordinários em diversos campos da Química. Foram concebidos métodos sintéticos para preparar moléculas cuja forma e tamanho dificilmente permitem que sejam descritas pelas regras de nomenclatura da IUPAC, e por isso são designadas pelos seus nomes triviais, muitas vezes inspirados nos objectos do dia a dia. Barris, cestos, cintos, pontes, caixas, cavidades, cárceres, sepulcros, esferas, vasos e fios, são exemplos destes nomes. Como consequência deste desenvolvimento a Química actual pode ocupar-se de sistemas mais complexos.

Pelo facto de ser um tema novo, não existe ainda um conceito universalmente aceite para a noção de Química Supramolecular ${ }^{2}$. Seguindo uma definição de um dos seus mais notáveis mentores, J. M. Lehn ${ }^{3}$, é a Química para além da molécula. En- quanto a Química tradicional se ocupa basicamente da ligação covalente, a Química Supramolecular é a Ciência das interacções entre moléculas, uma espécie de Sociologia Molecular. Como exemplo, enquanto a coordenação de ligandos ao metal é o objecto de estudo da Química de Coordenação, as interacções na segunda esfera de coordenação são objecto da Química Supramolecular. Ainda numa imagem de J. M. Lehn, átomo, molécula e supramolécula estão numa relação semelhante à letra, palavra e frase. A Química Supramolecular será nesta analogia o estudo do significado das frases. A Química Supramolecular pode ainda ser vista como o estudo das mudanças qualitativas em quantitativas, onde 1+1 não é necessariamente igual a dois. Na Química Supramolecular sobe-se do simples para o complexo, um movimento que curiosamente é o contrário da Bioquímica que desceu do complexo para o simples. O futuro dirá se estes dois movimentos se irão ou não encontrar algures em qualquer ponto da complexidade.

Numa linguagem muito corrente da Química Supramolecular ${ }^{3}$ os componentes de uma supramolécula são designados por substrato e receptor, este último o de maiores dimensões. Sendo, como acima se afirmou, a Química Supramolecular uma espécie de sociologia molecular, o reconhecimento molecular é a sua essência. Para darmos um exemplo de reconhecimento, consideremos um dado macrociclo em presença de uma mistura de iões halogeneto. Se o macrociclo complexar o fluoreto com uma constante de associação várias ordens de grandeza superior à dos restantes aniões dessa família, podemos afirmar que o macrociclo reconheceu o fluoreto. Designa-se reconhecimento molecular como a energia e a informação envolvidas numa ligação (supramolecular). Uma simples ligação não é reconhecimento embora muitas vezes seja tomada como $\mathrm{tal}^{3}$. Para haver reconhecimento será necessário um termo comparativo e alguma "mais valia" na ligação.
A expansão da Química Supramolecular nesta última década é impressionante. Cada vez mais grupos de investigação aderem a este ramo da Química. Pode dizer-se que se está tornando uma moda. E neste ponto está a questão mais polémica desta nova Ciência. É mesmo algo de novo, ou uma gigantesca operação de marketing científico, dando novos rótulos a coisas já existentes?

Com o objectivo de ilustrar alguns aspectos da Química Supramolecular, com especial relevo para a fotoquímica supramolecular, apresentamos alguns exemplos, sempre que possível baseados na nossa própria investigação. Deixemos ao leitor o julgamento do que há de "novo" na Química Supramolecular.

\section{MACROCICLOS E CRIPTANDOS}

Desde a década de sessenta que os macrociclos são usados como receptores de catiões. Os macrociclos são estruturas moleculares muitos importantes na Química e Bioquímica. Basta lembrar que a clorofila e a hemoglobina, ambas contêm um macrociclo (uma porfirina) que coordena respectivamente ião magnésio e ião ferroso. O grande desenvolvimento da química dos macrociclos começou com a síntese dos éteres coroa (fig. 1-a) por Pederson ${ }^{4}$ em 1967, e a descoberta de que as suas cavidades bidimensionais possuiam uma grande capacidade para complexação de catiôes. A capacidade que alguns macrociclos possuem para formarem aductos mais estáveis do que os parentes de cadeia aberta foi designada por efeito macrocíclico. Ainda nos finais dos anos sessenta Lehn e colaboradores 5 , sintetizaram um macrobiciclo(criptando), fig. 1-c que definia uma cavidade tridimensional particularmente apropriada para inserir catiōes alcalinos e alcalino-terrosos (criptato), mas também aniões ou moléculas neutras.

Em comparação com macrociclos naturais ou de síntese, os criptatos podem possuir estabilidades superiores em algumas ordens de gran- 

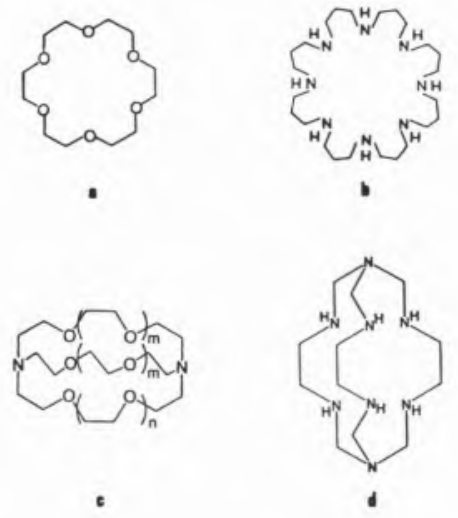

Figura 1 - Exemplos de receptores

supramoleculares. a- éter coroa, b-macrociclo poliaza, c- criptando, d- sepulcrato

deza. Além disso possuem uma elevada selectividade que depende da complementaridade das dimensões do receptor e do substrato.

A síntese de macrociclos de grandes dimensões do tipo poliaza6-8 (fig. 1-b), capazes de coordenar complexos metálicos aniónicos, assim como os sepulcratos sintetizados por Sargeson ${ }^{9}$, (fig. 1-d) onde se podem inserir metais de transição como o cobalto e a platina, deram origem a outros receptores supramoleculares particularmente importantes.

\section{COORDENAÇÃO \\ DE SUBSTRATOS ANIÓNICOS}

Apesar da importância química e biológica das espécies aniónicas, e ao contrário dos iões metálicos e dos catiões, existe um menor conhecimento no que respeita à ligação anião-receptor. No entanto, é de esperar que a Química Supramolecular envolvendo aniões dê origem a novas estruturas que apresentem propriedades com interesse químico e biológico. Um exemplo deste tipo de estruturas 10-14 é representado na Figura 2. O receptor macrocíclico o composto poliaza [32] ano- $_{8}$, previamente referenciado na fig. $1-b$, e o substrato constituido por compostos de coordenação do tipo $\mathrm{M}(\mathrm{CN})_{5} \mathrm{X}^{\mathrm{n}-\text {, }}$ $\mathrm{M}=\mathrm{Co}, \mathrm{Cr}$, Fe, $\mathrm{Ru}$, e $\mathrm{X}=\mathrm{CN}, \mathrm{H}_{2} \mathrm{O}, \mathrm{Br}$ etc...
A inserção dos compostos de coordenação no macrociclo, é assegurada por pontes de hidrogénio envolvendo os átomos de azoto protonados do macrociclo e os azotos dos ligandos cianeto. Apesar de só afectar ligeiramente os espectros de absorção U.V.-Vis. do substrato, a complexação na segunda esfera de coordenação do metal altera profundamente outras das suas propriedades. Por exemplo na supramolécula, o rendimento quântico para a reacção de fotoaquação do

$$
\mathrm{Co}(\mathrm{CN})_{6}{ }^{3-} \stackrel{\mathrm{hv}}{\rightarrow} \mathrm{Co}(\mathrm{CN})_{5}\left(\mathrm{H}_{2} \mathrm{O}\right)^{2-}+\mathrm{CN}^{-}
$$

composto $\mathrm{Co}(\mathrm{CN})_{6}^{3-}$ é reduzida na supramolécula de 0,3 para $0,1^{10,11}$ devido ao facto de quatro dos seis ligandos cianetos estarem impedidos de se dissociar, e por consequência de serem substituídos pelo ligando água, ver Figura 2. A oxidação do $\mathrm{Fe}(\mathrm{CN})_{6}^{4-}$ é mais positiva na presença do macrociclo de cerca de $165 \mathrm{mV}^{14}$. Este resultado é explicado pelo efeito

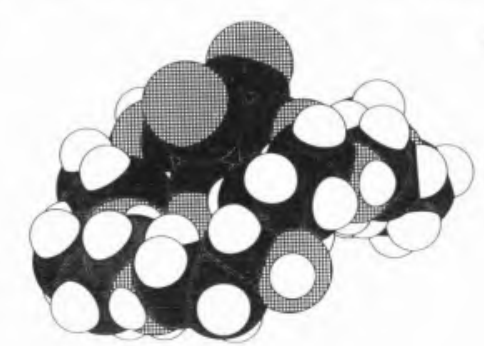

I)

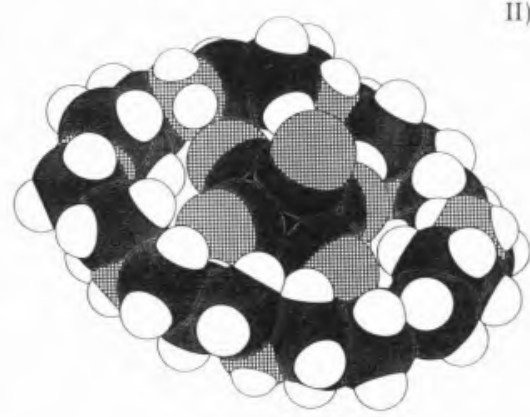

Figura 2 - Possíveis estruturas moleculares resultantes da inserção no receptor macrociclo poliaza [32]-ano $\mathrm{N}_{8} \mathrm{H}_{8}^{8+}$, nos substratos dos seguintes tipos: a) $M(C N)_{6}^{n-}, M=F e(n=3,4)$, $\mathrm{Ru}(\mathrm{n}=4)$ e $\mathrm{Co}(\mathrm{n}=3)$, b) $\mathrm{M}\left(\mathrm{CN}\left(\mathrm{H}_{2} \mathrm{O}\right)\right)_{5}^{2-} \mathrm{M}=\mathrm{Co}, \mathrm{Cr}$ c) $\mathrm{Co}(\mathrm{CN}) \mathrm{X}_{5}^{3-} \mathrm{X}=\mathrm{Cl}, \mathrm{Br}$ electrostático resultante da maior carga positiva que circunda o metal no supracomplexo tornando a oxidação mais difícil e portanto mais anódica.

No caso do substrato $\mathrm{Co}(\mathrm{CN}) \mathrm{Br}_{5}^{3-}$ a reacção térmica de aquação, que consiste na substituição do ligando brometo pelo ligando água é praticamente inexistente na supramolécula,

$$
\mathrm{Co}(\mathrm{CN})_{5} \mathrm{Br}^{3-} \stackrel{\text { hv }}{\rightarrow} \mathrm{Co}(\mathrm{CN})_{5}\left(\mathrm{H}_{2} \mathrm{O}\right)^{2-}+\mathrm{Br}^{-}
$$

e a reacção de fotoaquação eq.(2), vem reduzida de 0,23 para $0,02^{11}$. Para explicar esta elevada redução, os argumentos estereoquímicos não são convincentes. Com efeito, analisando a posição do ligando brometo na supramolécula, verifica-se que: i) ou está envolvido nas ligações de hidrogénio (o que à partida não é provável), e nesse caso a redução de fotoaquação deveria ser total, ii) ou não está envolvido nessas ligações e nesse caso não deveria ser esperado qualquer efeito estereoquímico que impedisse a sua saída. Se não é então um efeito estereoquímico, outro motivo haverá que explique uma tão elevada redução. Tendo em conta que se trabalha a $\mathrm{pH}<6$ para permitir a protonação de todos os átomos de azoto do macrociclo, aquilo que distingue o ligando cianeto do ligando brometo é a carga. No caso do ligando brometo a carga é sempre - 1 , independente do $\mathrm{pH}$, ao passo que no ligando cianeto a protonação deverá ocorrer logo após a dissociação, dado que $\mathrm{pH}<\mathrm{pK}_{\mathrm{a}}$ do $\operatorname{HCN}(8,68)$. Como o macrociclo totalmente protonado possui uma carga de +8 , o efeito electrostático é a explicação mais evidente para este efeito.

Quanto ao substrato $\mathrm{Cr}(\mathrm{CN})_{6}^{3-}$ que térmica e fotoquimicamente sofre aquações sucessivas dos ligandos cianeto para dar o produto final totalmente hidratado, as velocidades e distribuições dos sucessivos produtos na supramolécula vêm profundamente alteradas 12 .

Finalmente foi ainda possível provar $^{13}$ que no caso do receptor 
macrocíclico [32] $]$ ano- $\mathrm{N}_{8}$ e do substrato $\mathrm{Co}(\mathrm{CN})\left(\mathrm{H}_{2} \mathrm{O}\right)_{5}^{2-}$ a estrutura em solução é do tipo cintura em vez de barco, fig.2-II.

Uma outra interessante família de receptores para aniões é a dos macrociclos poliazociclofano ${ }^{15}$, Figura 3.

Estes macrociclos, que possuem cavidades muito pequenas, coordenam catiões como o $\mathrm{Cu}^{2+}$ e $\mathrm{Zn}^{2+}$, e também aniões como o $\mathrm{Co}(\mathrm{CN})_{6}^{3}$; através de pontes de hidrogénio envolvendo três dos ligandos cianeto. Apresentam ainda uma outra interessante propriedade que é o facto de ao contrário dos seus parentes po-
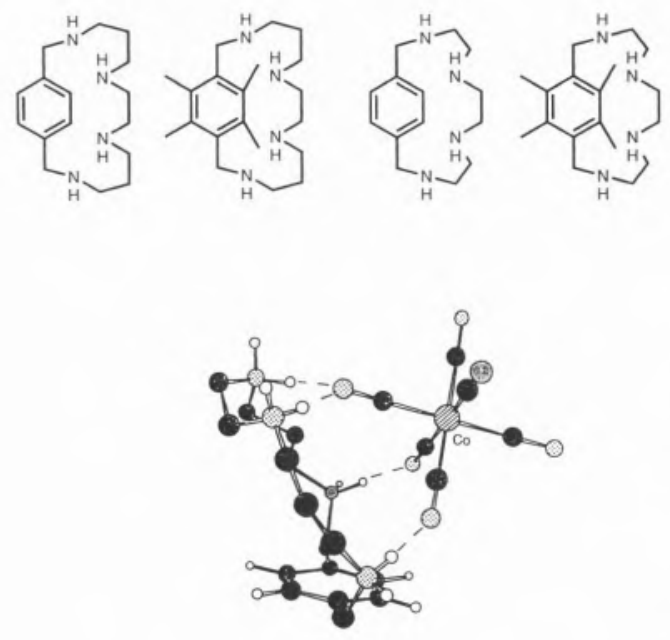

Figura 3 - Receptores macrocíclicos do tipo poliazaciclofanos. Em baixo estrutura propost para a interaç̧ão com $\mathrm{Co}(\mathrm{CN})_{6}^{3-}$

liaza, acima referidos, possuirem emissão de fluorescência devido à presença do anel de benzeno na estrutura. Tal facto permite utilizar a técnica de emissão de fluorescência em estudos de complexação com as vantagens daí inerentes.

Concluimos destes exemplos que o processo de reconhecimento pode modificar o curso de uma reacção alterando a velocidade ou a natureza dos produtos. Neste caso o reconhecimento é expresso não só pela energia da ligação supramolecular, mas também pela transformação química, que é modificada na sua natureza ou velocidade.

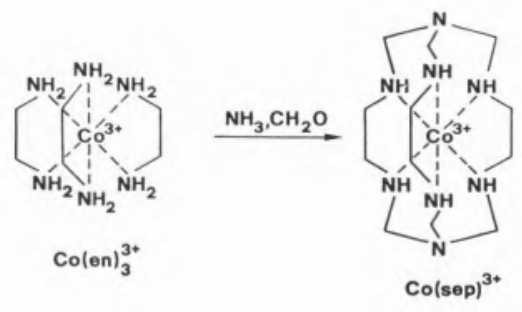

Figura 4 - Reacção de formação do sepulcrato de cobalto a partir de $\mathrm{Co}(\mathrm{en})_{3}^{3+}$

\section{ENCAPSULAÇÃO DE METAIS}

É do conhecimento geral que os compostos de coordenação de Co(III) são cineticamente inertes enquanto que os de Co(II) são muitos lábeis por causa da presença de electrões nas orbitais antiligantes $\sigma^{*} \mathrm{M}\left(\mathrm{e}_{\mathrm{g}}\right)$. Como consequência a redução do ião metálico no composto $\mathrm{Co}\left(\mathrm{NH}_{3}\right)_{6}^{3+}$ dá origem a uma rápida decomposição que conduz ao ião aquoso $\mathrm{Co}_{\mathrm{aq}}^{2+}$. $\mathrm{O}$ mesmo se passa com o composto análogo de etilenodiamina $\mathrm{Co}(\mathrm{en})_{3}^{3+}$ ente para estabilizar o estado de oxidação (II) do metal. Sargeson ${ }^{9}$ e colaboradores publicaram em 1977 a síntese do sepulcrato de cobalto, fig. 4 .

O sepulcrato de cobalto apesar de U.V.-Vis semelhante ao análogo trietilenodiamina, possui propriedades indicando que a quelação é insuficiapresentar um espectro de absorção redox completamente diferentes sendo possível obter de forma estável a espécie reduzida, $\mathrm{Co}(\mathrm{Sep})^{2+}$. Esta nova propriedade permite usar o sepulcrato de cobalto como transportador de carga em ciclos fotoquímicos de produção de iodo $^{16}$ ou hidrogénio ${ }^{17}$, ou em ciclos para a oxidação suave com oxigénio de substratos que são directamente oxidáveis pelo iodo (mas não directamente pelo oxigénio) ${ }^{18}$, Figura 5.

\section{CALIXARENOS, CAVITANDOS, CARCERANDOS E HEMICARCERANDOS}

Como já foi atrás referido, as moléculas do tipo esférico contendo cavidades tridimensionais a exemplo dos criptandos, atrairam desde logo a atenção dos Químicos. Algumas dessas cavidades são tão pequenas que não comportam mais do que um ião metálico. Mais recentemente foram, no entanto, sintetizadas algumas moléculas contendo cavidades de maiores dimensões de modo a albergar iões diversos e moléculas neutras. Uma das famílias mais interessantes é a dos carcerandos e hemicarcerandos sintetizados por $\mathrm{Cram}^{19}$. A estratégia de síntese dessas moléculas consiste em utilizar os calixarenos, oligómeros cíclicos construídos com anéis benzénicos, e destes obter por rigidificação um cavitando 20 , figura 6 .
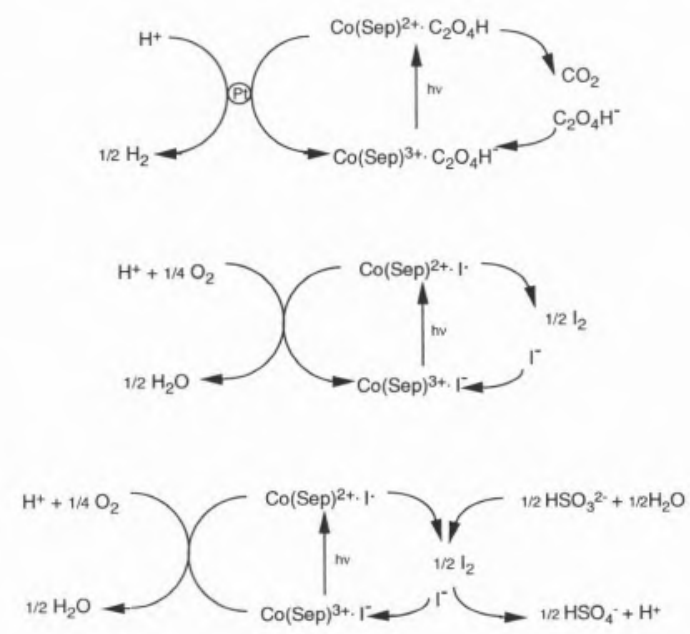

Figura 5 - Exemplos de ciclos fotocatalíticos envolvendo o Sepulcrato de cobalto 
A junção de dois cavitandos através de pontes dá origem a carcerandos e hemicarcerandos. Os carcerandos podem aprisionar outras moléculas, geralmente o solvente, de um modo irreversível. Os hemicarcerandos são espécies contendo portões através dos quais podem entrar moléculas a alta temperatura, e permanecer dentro da cavidade à temperatura ambiente por tempos mais ou menos longos.

Os carcerandos e os hemicarcerandos são espécies muito importantes para a Fotoquímica Supramolecular porque oferecem a oportunidade de estudar o comportamento do estado excitado de substratos isolados no ambiente específico da cavidade. Esta circunstância dá origem a novas e por vezes espectaculares propriedades da molécula aprisionada (substrato), facto que levou Cram a considerar a cavidade dos carcerandos e hemicarcerandos como $\mathrm{um}$ novo estado da matéria.

Dois exemplos destas novas propriedades são a prisão do 9-cianoantraceno ${ }^{20}$ no hemicarcerando 1 , e a do biacetilo 22 no hemicarcerando 2 .

Os dois hemicarcerandos são constituídos por bases idênticas, mas pontes diferentes, o que dá origem a dimensões da cavidade completamente diversas. Em termos gerais, moléculas de dimensões reduzidas podem entrar nas cavidades, mas não conseguem permanecer aí dentro. Moléculas de dimensões elevadas para o tamanho da cavidade não entram. Por outro lado a própria forma das moléculas é importante. No caso do hemicarcerando 1 elas devem ser mais compridas do que largas. Para o hemicarcerando 2 quase do tipo esférico. O reconhecimento molecular nestas moléculas torna-se bastante restrito.

A maior evidência para a prisão dos substratos nos receptores deriva dos espectros de ${ }^{1} \mathrm{H}$ RMN. Após a encarceração são claramente visíveis desvios químicos tanto no receptor como no substrato. A corrente de anel das duas bases do hemicarcerando, dá origem a elevados desvios químicos para campo
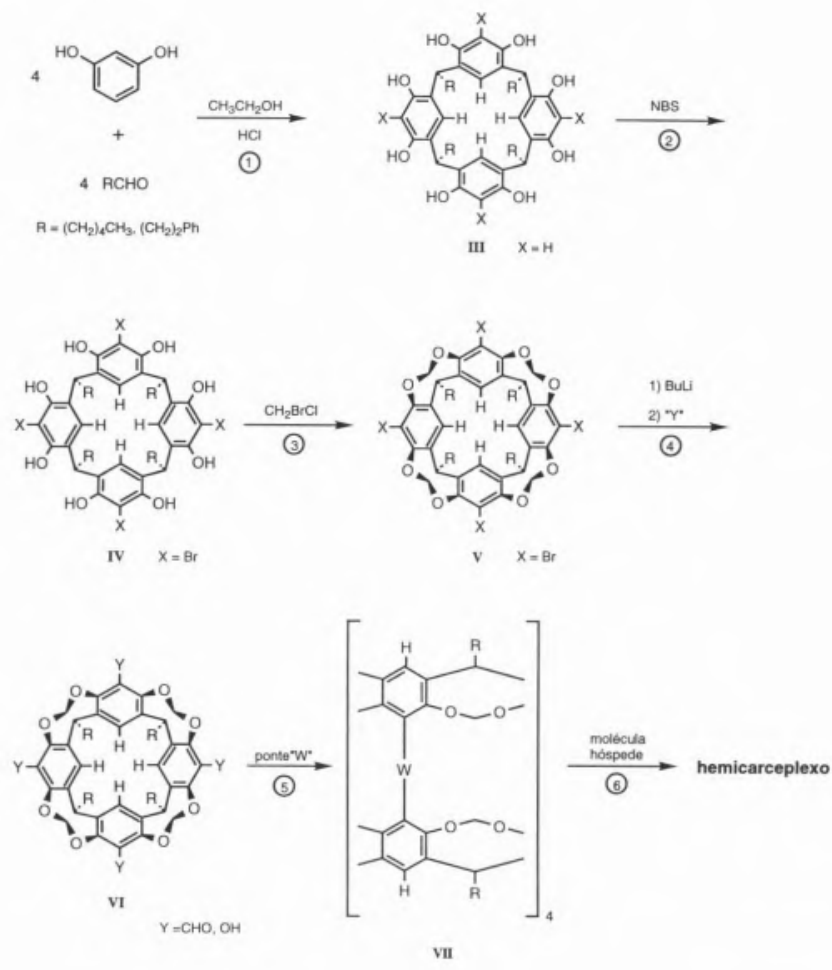

Figura 6 - Estratégia de síntese de um hemicarcerando a partir de um calixareno.
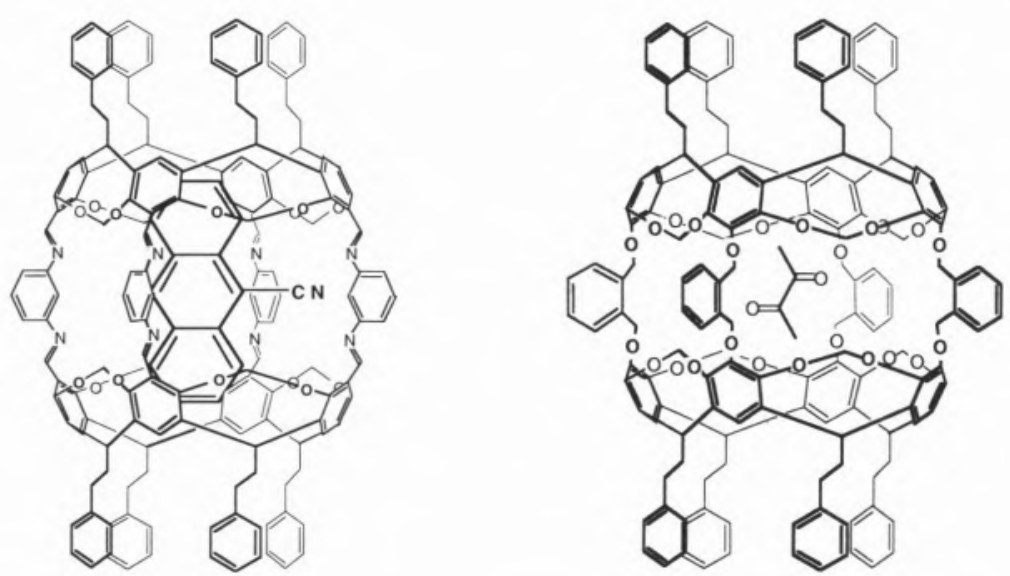

Figura 7 - Dois exemplos de hemicarceplexos. Em ambos os casos as bases são idênticas. No hemicarcerando 1 a ponte é constituída por grupos imina e no hemicarcerando 2 por grupos benzil.

alto, dos protões do substrato delas vizinhos. Por outro lado os protões do hemicarcerando que estão virados para dentro sofrem desvios devidos à presença do substrato.

No caso do hemicarceplexo ob- tido pela prisão de 9-cianoantraceno, verificou-se que a simetria $\mathrm{D}_{4} \mathrm{~h}$ observada no espectro de ${ }^{1} \mathrm{H}$ RMN do hemicarcerando era quebrada para $\mathrm{C}_{2 \mathrm{v}}$ no hemicarceplexo. Este facto permitiu concluir que o 9-cia- 
noantraceno ao contrário de todos os outros casos anteriormente referidos na literatura, não roda dentro da cavidade, ficando o grupo ciano à janela na cavidade.

A cavidade protege o 9-cianoantraceno do efeito de supressão de fluorescência de moléculas dissolvidas na solução exterior. Por exemplo o $\mathrm{DBN}^{23}$ é um eficiente supressor da fluorescência do 9-cianoantraceno livre, mas não tem qualquer efeito na emissão de fluorescência da mesma molécula dentro da cavidade. Por outro lado a cavidade também modifica intensamente as propriedades de absorção e de emissão do 9-cianoantraceno. Neste último caso o rendimento quântico de fluorescência é reduzido na cavidade de cerca de 50 vezes e o tempo de vida passa de 15 ns para 350 ps.

O biacetilo é uma molécula muito interessante para os Fotoquímicos devido ao facto de ser uma das poucas a emitir fosforescência à temperatura ambiente. Por motivo do elevado tempo de vida desta espécie, pequenas concentrações de oxigénio dão origem a enormes diminuições na sua intensidade de fosforescência. E este é um problema bem conhecido por todos aqueles que já usaram a emissão do biacetilo, por exemplo para foto-sensibilizar estados de tripleto de outras moléculas. Um desarejamento muito eficiente é uma das condições para obter esta belíssima emissão, e por conseguinte a foto-sensibilização. Surpreendentemente o oxigénio não suprime a fosforescência do biacetilo quando dentro do hemicarcerando. Por outro lado a perturbação da cavidade nas propriedades de absorção U.V.-Vis. do biacetilo é menor do que a dos solventes mais "inocentes". Do ponto de vista aplicativo a ausência do efeito supressor do oxigénio numa emissão intensa e de longo tempo de vida abre a porta a uma nova família de sondas luminescentes particularmente para testes de imunofluorescência.

Nos próximos anos teremos certamente oportunidade de conhecer como variam outras propriedades das moléculas encarceradas, e é muito provável que algumas surpresas nos estejam reservadas. Estas são um dos motivos pelos quais a Ciência e a Química em particular apaixonam tanta gente!

\section{CONCLUSÃO}

Uma conclusão necessariamente provisória é a de que está aberto um novo percurso para a Química em geral e para a Fotoquímica em particular. É ainda cedo para avaliar todas as implicações desta nova química em dispositivos moleculares para a conversão de energia, nos nano-materiais etc. Mas decerto que uma boa parte do futuro da química vai passar por aqui.

\section{AGRADECIMENTOS}

O desenvolvimento da Química Supramolecular na FCT-UNL não teria sido possível sem por um lado, a colaboração com o grupo do Prof. Balzani, da Universidade de Bolonha e por outro a de todos os investigadores que têm passado ou permanecem no grupo. Destes gostaria de destacar o Dr. A. Jorge Parola pelo seu constante e profícuo labor na síntese dos hemicarcerandos, hemicarceplexos e macrociclos poliaza, o Prof. João Sotomayor e a Dr. Alexandra Bernardo respectivamente no estudo dos ciano derivados de crómio e nos poliazaciclofanos e a Dra. Maria João Melo pelo seu imenso criticismo e pelas contribuições num trabalho que só marginalmente toca o seu tema de doutoramento. Finalmente gostariamos de agradecer ao Prof. Garcia-España e seus colaboradores (Universidade de Valência-Espanha), a síntese dos poliazaciclofanos.

\footnotetext{
* Faculdade de Ciências e Tecnologia Universidade Nova de Lisboa Quinta da Torre 2825 Monte de Caparica
}

\section{REFERÊNCIAS}

1. V. Balzani, F. Scandola, Supramolecular Photochemistry, Ellis Horwood, (1991).

2. Sobre outros conceitos de Química Supramolecular consultar R. Delgado, Rev. Port. Quim. 2 (1995), 18-29.

3. I.-M. Lehn, Supramolecular Chemistry, VCH, (1995).

4. C. I. Pederson, J. Amer. Chem. Soc. 89 (1967), 2495 $-7017$

5. B. Dietrich, 1.-M. Lehn, I. P. Sauvage, Tetrahedron (1969), 2885, 2889.

6. I. E. Richman, T. I. Atkins I. Amer. Chem. Soc. 96 (1974), 2269.

7. B. Dietrich, M. W. Hosseini, I. M. Lehn, R. B. Sessions, J. Amer. Chem. Soc. 103 (1981), 1282

8. A. Bianchi, M. Micheloni, P. Paoletti, Pure \& Appl. Chem. 60 (1988), 525.

9. A. M. Sargeson, Pure \& Appl. Chem. 56 (1984), 1603.

10. M. F. Manfrin, L. Moggi, V. Castelvetro, V. Balzani, M. H. Hosseini, I.-M. Lehn I. Amer. Chem. Soc. 107 (1985). 6888 .

11. F. Pina, L.Moggi, M.Manfrin, V.Balzani, M. Hoseini I.M.Lehn, Gazzeta Chimica Italiana, 119 (1989) 65-67.

12. J. Sotomayor, J. Parola, F. Manfrin, L. Moggi, P. Riceri, E. Zinato, F. Pina, Inorg. Chem. 34 (1995) 6532-6537.

13. A. J. Parola, F. Pina, 1. Photochem. Photobiology, 66. (1992), 337-343.

14. M. W. Hosseini in Perspectives in Coordination Chemistry, ed. A.F. Williams, C. Floriani, A. E. Merbach, $\mathrm{VCH}$.

15. M. A. Bernardo, A.J. Parola, F. Pina, E. Garcia - España, V. Marcelino, S. V. Luís, J. F. Miravet /. Chem. Soc. Dalton, (1995), 993-997.

16. F. Pina, Quinto G. Mulazzani, M. Venturi, M. Ciano, V. Balzani Inorg, Chem. 24 (1985), 848-851; F. Pina, M. Maestri, R. Ballardini, Q. G. Mulazzani, Mila D'Angelantonio, V. Balzani, Inorg. Chem. 25 (1986), 4249-4252,

17. F. Pina, M. Ciano, L. Moggi, V. Balzani, Inorg. Chem. 24 (1985), 844-847.

18. P.Figueiredo, F. Pina, 1. Photochem. Photobiology, A: Chemistry, 44 (1988), 57-61.

19. D. I. Cram, Nature, 356 (1992), 29.

20. R.C. Helgeson, I-P. Mazaleyrat, D. Cram, C D. I. Cram, S. Karbach, H-E. Kim, C.B.Knobler, E.F. Maverich, J.L. Ericson, R.C. Helgeson, I. Amer. Chem. Soc. 110 (1988), 2229.

21. A. J. Parola, F. Pina, M. Maestri, N. Armaroli, V. Balzani, New, I. Chem, 18 (1994), 659-661.

22. F. Pina, A. J. Parola, E. Ferreira, M. Maestri, N. Armaroli, R. Balardini, V. Balzani J. Phys. Chem. 99 (1995), 12701-12703.

23. 1,5-diazabiciclo[4.3.0]non-5-eno (DBN) é um eficiente agente de supressão da fluorescência do biacetilo livre. 


\section{CURSOS \\ DE QUIMICA \\ ANALITICA}

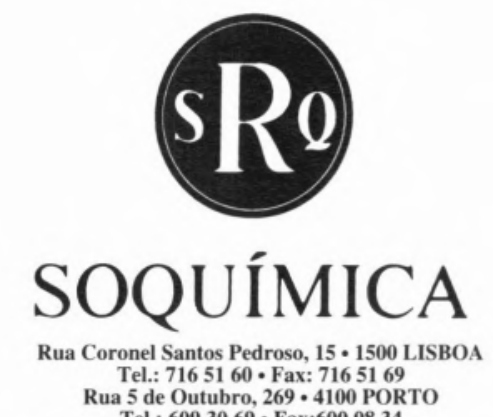

Rua 5 de Outubro, $269 \cdot 4100$ PORTO

el.: $6093069 \cdot$ Fax:600 0834

Cromatografia de Fase Líg̨uida-HPLC

Tratamento de Dados Cromatográficos por Computador (Aperfeiç0anento)

Cromatografia de Gases (Iniciação)

ESPECTROFOTOMETRIa de UV-VIs (INiCiaç̃̃o)

Cromatografia de Gases (APERfeiçoanento)

Espectrof0t0METRia de Uv-Vis (APERFEIÇ0AMENT0)

P0tencionetria (Iniciação)

Calibraç̃̃o de Espectofotómetros

P0tencionetria (APERFeiç0AMENT0)

Introdução A MÉtodos ViscosivÉtricos BR00KFIELD

Iniciação a0s Sistevas de Tratamento de Dados para Cromatografia

Tratanento de Dados Cromatográficos p0r Integrador (Aperfeiç0avento) Cursos Especials para Eupresas

\section{JANEIR0/DEZEMBR0 1996}

